\title{
A Briggs-Rauscher Reaction-based Spectrometric Assay to Determine Antioxidant Content in Complex Matrices in Low Technology Environments
}

\author{
Ankit Singhal*a, Philipp Gröglib, Bernd Geiser ${ }^{b}$, and Alina Handl ${ }^{b}$
}

\begin{abstract}
The Briggs-Rauscher (BR) reaction is free radical based where the kinetics of formation of different iodide species leads to potentiometric and color oscillations. These oscillations were monitored in this study using a UV/Vis attenuated total reflection probe to develop an assay to measure the antioxidant content in complex matrices. The periodicity of the BR reaction was found to be very consistent (range 24-25 seconds, $n=16$ ). Adding various amounts of ascorbic acid, a well-known antioxidant, led to an inhibition of the reaction with a linear calibration curve of antioxidant periodicity time (APT, $r^{2}>0.99$ ). The validity of this test in complex matrices was studied by determining the APT of nine fruits, and the resulting antioxidant capacity in ascorbic acid equivalency was calculated. The results generated by this assay were found be accurate through comparison with the well-established FRAP assay. These results show that visual or spectrometric monitoring of BR reaction can be used as a reliable, quick, and inexpensive alternative to more established assays with the added advantage that values generated from this assay is at $\mathrm{pH} 2$ which is similar to that in the human stomach.
\end{abstract}

Keywords: Antioxidant · Ascorbic acid · Briggs-Rauscher · Spectrometric assay

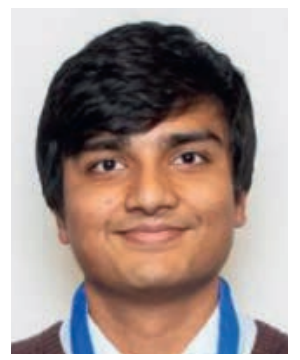

Ankit Singhal is currently a gymnasium (high school) student at the International School of Basel. This research project was initiated for the Swiss Young Naturalist Tournament (SYNT), an annual competition held at MNG Rämibühl, Zurich. On March 7, 2020 this research was presented and awarded the first prize at the SYNT 2020 competition. More details can be found on https:// www.synt.ch/index.php/synt/synt-2020.

\section{Introduction}

Antioxidants have been widely proven to show beneficial effects on the human body. ${ }^{[1-3]}$ Thus, the accurate, quick and cheap determination of antioxidants present in complex naturally occurring matrices, such as fruits and vegetables, has been an area of continued focus. For example, a new approach based on synthetized $\mathrm{MnO}_{2}$ nanosheets to determine antioxidant levels was proposed as recently as earlier in 2020. ${ }^{[4]}$ There are three main challenges to determine antioxidant present in food and nutraceuticals: a) there is huge chemical diversity of antioxidants (phenols, thiols, carboxylic acids, carotenes, etc.), so any test must account for different chemical structures that contribute to antioxidant properties of that particular food group; b) the matrices of foods are a complex mixture of cellulosic material, lignin, vitamins, phytochemicals, etc. so interference from these water-soluble materials is an issue during measurements; and c) antioxidants are intrinsically unstable due to their rapid oxidation, thus, the test must be quick and simple, particularly if being conducted in an agricultural setting.

Several accurate and reliable assays have been developed to measure antioxidants in complex matrices. ${ }^{[5-7]}$ These tests can be divided in two broad categories of either general assays that measure the total antioxidant capacity (TAC) or specific assays for individual antioxidants. General assays, much more commonly used than specific assays, fall into two subclasses depending on the underlying chemical mechanisms: either into the reactive oxygen species scavenging assays (ROSS assays such as the widely used ORAC) or the redox potential assays (such as the widely used FRAP). ORAC (oxygen radical absorbance capacity) uses peroxy radical generated using fluorescein as a probe while FRAP (ferric reducing antioxidant power) is based on the reduction of an $\mathrm{Fe}$ (III) to $\mathrm{Fe}(\mathrm{II})$ ion using ferricyanide as a probe. Both these tests are commercially available as kits but are expensive and may be out of reach for many parts of the world. These TAC tests can be routinely done in a laboratory environment, however, it needs sophisticated equipment in fluorometry, electron paramagnetic resonance, cyclic voltammetry or sensitive spectroscopic measurements. Similar specialized equipment is also needed for specific antioxidant tests; they typically include high performance liquid chromatography (HPLC) system to separate antioxidants from natural interfering matrices and then coupling the elute from HPLC with a diode-array-detector, mass spectroscopy or fluorescence detector for the detection of antioxidants. Developing a HPLC method free from interfering complex food matrix and running this equipment requires specialized knowledge that is not widely available in many geographically isolated parts of the world. A reliable, cheaper and quick method to estimate TAC in complex natural matrix will benefit the agricultural community and other rural communities to maximize antioxidant potential of fruits and vegetables during its harvest, transport, storage and distribution.

Positive aspects of current commercial assays are a good guide to design improvements in future assays. Based on this, there are 
at least three critical design elements to designing a new reliable, cheaper and quick method. First, the underlying principle should involve free radical mechanisms resulting in a clear response when antioxidant is added; second, the resulting end point due to changes in free-radical species should be easy to detect (ideally visually); lastly, the assay should be easy to set up and the reagents involved should be cheap, safe, and easily accessible. One reaction that fits all of these three criteria is the oscillating Briggs-Rauscher (BR) reaction published in 1973. ${ }^{8]}$ The oscillatory free-radical change in the BR reaction can be observed either through a very quick redoxpotential change or through cyclical color changes from colorless to amber to a blue-black color. The redox potential oscillations in BR has been widely studied using potentiometric methods. Each potentiometric cycle is reliable, typically lasting 10-30 seconds, thus potentiometric methods have been developed to study the antioxidant concentration in complex matrices. ${ }^{[9-15]}$ However, potentiometric measurement require platinum, silver or other similar electrodes that are not readily available in educational settings. This idea of using BR reaction to quantify antioxidant can be made simpler for use to the wider student and agricultural communities if potentiometric measurements can be replaced by color change, which can be monitored visually or be coupled with a simple spectrometer that is widely available. Thus, in this study, the feasibility of using color change in BR reaction is studied as a possible approach to determine antioxidant content in complex matrices. If successful, this will not only develop a new assay that is cheap and easy to do, it is easily implementable in all educational settings (particularly at high schools as needed) to show the beauty of applying a simple reaction to solve a complicated problem and help energize students to aspire to study chemistry.

\section{Experimental Section}

\subsection{Reagents and Chemicals}

All reagents and chemicals used in this study were purchased from commercial sources. Ascorbic acid (vitamin C) was USP grade and manufactured by DSM Nutritional Products Ltd (UK). This was used as a standard for generating the calibration curve. Potassium iodate used was $99.5 \%$ pure from Acros Organics, Malonic acid was $\geq 99 \%$ pure from Fisher Chemical and manganese sulphate monohydrate was ACS reagent $\geq 98 \%$ pure from Sigma-Aldrich. Starch soluble grade was manufactured by Merck. Hydrogen peroxide was sourced as $30 \%$ aqueous solution, nonstabilized, from Acros Organics. Deionized water was used in all experiments.

Three solutions were prepared for the BR reaction:

Solution A (potassium iodate) was prepared by dissolving approximately $43 \mathrm{~g}$ potassium iodate $\left(\mathrm{KIO}_{3}\right)$ in $1000 \mathrm{~mL}$ deionized water as the reaction is sensitive to chloride ions. The $\mathrm{pH}$ was adjusted to 2-3 by addition of approx. $9 \mathrm{~mL}$ of sulfuric acid.

Solution $B$ (malonic acid with manganese sulphate) was prepared by dissolving $15.6 \mathrm{~g}$ malonic acid and $3.4 \mathrm{~g}$ manganese sulfate monohydrate first in approx. $800 \mathrm{~mL}$ deionized water. $4 \mathrm{~g}$ of starch was then added and stirred until dissolved. The final volume was adjusted to $1000 \mathrm{~mL}$ with water.

Solution $C$ (12\% hydrogen peroxide) was prepared by diluting $30 \%$ stock aqueous hydrogen peroxide with water to make $1000 \mathrm{~mL}$ of $12 \%$ hydrogen peroxide final solution.

\subsection{UV/Vis Spectrophotometer Probe}

An attenuated transmission reflectance spectroscopic probe attached to a UV/Vis spectrophotometer (Carl-Zeiss) was used for these experiments. These probes are widely available and used in many applications such as pure inks, dyes, oil samples, etc. The probe was inserted directly into the test tube where the reaction occurs. UV absorbance at $250 \mathrm{~nm}$ (amber) and $350 \mathrm{~nm}$ (black blue) were collected to monitor the color of solution.

\subsection{Experimental Set-up}

The experimental set-up used in this study is shown in Fig. 1. The $\mathrm{BR}$ reaction was initiated by adding $3 \mathrm{~mL}$ of solution $\mathrm{C}$ to premixed $3 \mathrm{ml}$ solution $\mathrm{A}$ and $3 \mathrm{~mL}$ solution $\mathrm{B}$ in a test tube that was continuously mixed using a magnetic stirrer on a stir plate. Each freshly prepared reaction mixture was allowed to come to regular periodicity by going through 2 cycles of color change as defined by appearance of the blue-black color. At the beginning of the third oscillation, 50 microliters of standard ascorbic acid solution or fruit juice was added. All fruit juices used in this study were freshly squeezed and filtered through a 5-micron filter just before each experiment. All experiments were done, at minimum, in triplicate.
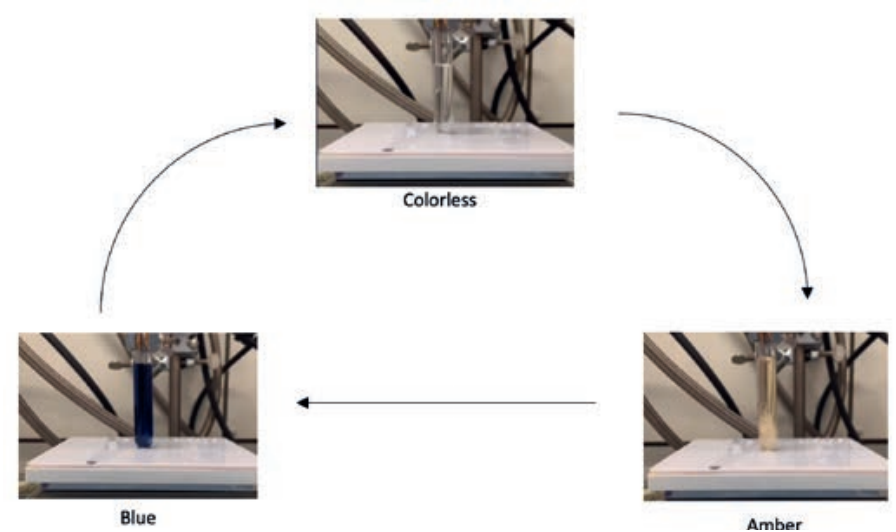

Fig. 1. Experimental set-up showing the three stages of the BR reaction as represented in Scheme 1. UV probe in the test tube was used to collect the absorbance at $250 \mathrm{~nm}$ and $350 \mathrm{~nm}$ to capture the color change.

\section{Results and Discussion}

\subsection{Blank BR Reaction and Effect of Antioxidant}

Freshly mixed BR reaction reagents resulted in clear solution as shown in Fig. 1 and then over the next 10-15 seconds the clear solution slowly turned to amber color and then abruptly changed to blue color. Subsequently, the blue color slowly faded away in the next 10-15 seconds to a colorless solution and this cycle of color change repeated. Scheme I shows the color in the BR reaction and underlying chemical species for the color. Formation of these chemical species, leading to the cyclical color change in the $\mathrm{BR}$ reaction, is complex and still not fully understood, although it is widely accepted that several slow non-radical and fast radical

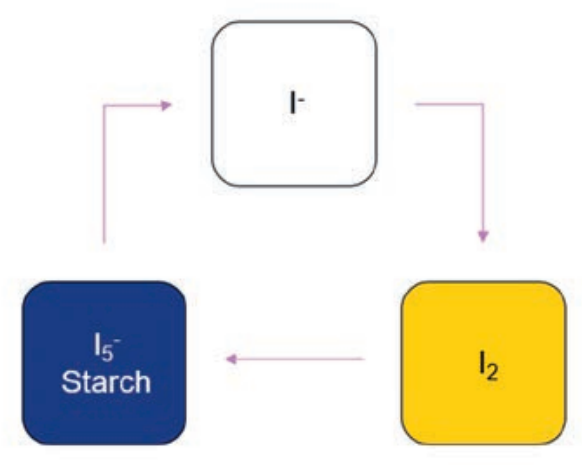

Scheme 1. Color change in BR reaction due to the different amount of active species in the reaction mixture. Reaction starts off as colorless, slowly converts to amber color, then abruptly to blue color that then slowly changes back to a colorless solution to continue the cycle to blue. 
reactions are occurring in parallel at varying rates that depend on changing concentrations of the iodide ions species present in the reaction. ${ }^{[16-20]}$ This sets up two different points of equilibrium and the switching of these two states creates the cyclical color change. The overall reaction can be depicted using Eqn. (1) where iodate, hydrogen peroxide and malonic acid at acidic $\mathrm{pH}$ in the presence of manganese ion as a catalyst react to produce iodomalonic acid at the end.

$$
\mathrm{IO}_{3}^{-}+2 \mathrm{H}_{2} \mathrm{O}_{2}+\mathrm{CH}_{2}(\mathrm{COOH})_{2}+\mathrm{H}^{+} \rightarrow \mathrm{ICH}\left(\mathrm{CO}_{2} \mathrm{H}\right)_{2}+2 \mathrm{O}_{2}+3 \mathrm{H}_{2} \mathrm{O}
$$

To understand the color change, Eqn. (1) is broken down into Eqns (2) to (4) below. These equations are still simple versions of the composite multiple underlying reactions.

$\mathrm{IO}_{3}^{-}+2 \mathrm{H}_{2} \mathrm{O}_{2}+\mathrm{H}^{+} \rightarrow \mathrm{HIO}+2 \mathrm{O}_{2}+2 \mathrm{H}_{2} \mathrm{O}$

$\mathrm{HIO}+\mathrm{CH}_{2}(\mathrm{COOH})_{2} \rightarrow \mathrm{ICH}(\mathrm{COOH})_{2}+\mathrm{H}_{2} \mathrm{O}$

$\mathrm{I}^{-}+\mathrm{HIO}+\mathrm{H}^{+} \rightarrow \mathrm{I}_{2}+\mathrm{H}_{2} \mathrm{O}$

$\mathrm{I}_{2}+\mathrm{CH}_{2}(\mathrm{COOH})_{2} \rightarrow \mathrm{ICH}(\mathrm{COOH})_{2}+\mathrm{H}^{+}+\mathrm{I}^{-}$

Eqn. (2) is the simplified equation where hypoiodous acid (HIO) is produced via a slow non-radical as well as a fast radical pathway. $\mathrm{HIO}$ is consumed by reacting with malonic acid $\left(\mathrm{CH}_{2}(\mathrm{COOH})_{2}\right)$ to form iodomalonic acid $\left(\mathrm{ICH}(\mathrm{COOH})_{2}\right)$ in Eqn. (3). These two equations are in balance when low amounts of $\mathrm{HIO}$ are produced in Eqn. (2) via the slow non-radical process. But when production of HIO increases quickly due to the faster radical process, HIO accumulates and the reactions shown in Eqns (4) and (5) start to dominate. Initially the iodide anion $\left(\mathrm{I}^{-}\right)$is the predominant species when reagents of the BR reaction are freshly mixed, so the solution is colorless. Then, as shown in Eqn. (4), an excess of HIO results in the production of elemental iodine $\left(\mathrm{I}_{2}\right)$ which leads to an amber color. As the concentration of the elemental iodine increases via Eqns (4) and (5), it forms a pentaiodide complex with iodide in high concentrations that binds with starch to create the blue-black color. Due to the fact that Eqn. (4) is faster than Eqn. (5), the iodide ion is consumed causing the pentaiodide-starch complexes to dissipate and leaving iodate as the primary species, thus changing the reaction back to a colorless state until enough elemental iodine is formed again to change the reaction to an amber color. This reaction continues periodically until either the iodate or malonic acid is completely consumed by the reaction, which typically takes $>10-20$ cycles. It is expected from these underlying free-radical mechanisms that antioxidants will decrease HIO produced via the fast radical process, and thus, disrupt the BR color cycle until all of the antioxidants are used up. This perturbation of the periodic color cycle can be seen easily visually or via a simple UV/Vis probe.

$\mathrm{UV} / \mathrm{Vis}$ spectra at $250 \mathrm{~nm}$ and $350 \mathrm{~nm}$ of the BR reaction are shown in Fig. 2. The blue color in the BR reaction corresponded to the peak at $250 \mathrm{~nm}$ and $350 \mathrm{~nm}$ while colorless solution shows up as the trough of each peak at $250 \mathrm{~nm}$ and $350 \mathrm{~nm}$. As expected from the intrinsic wavelength of the blue-black color, $350 \mathrm{~nm}$ was more discriminating to pick up the color change in the BR reaction, and thus was used for all future experiments. The periodicity of each cycle, defined by length of time between two consecutive blue-black appearances (peak to peak at $350 \mathrm{~nm}$ ), is also shown in Fig. 2. The first cycle tended to be the slowest while second cycle was more consistent with values in the steady state but not yet like clockwork showing that the BR reaction needed the first two cycles

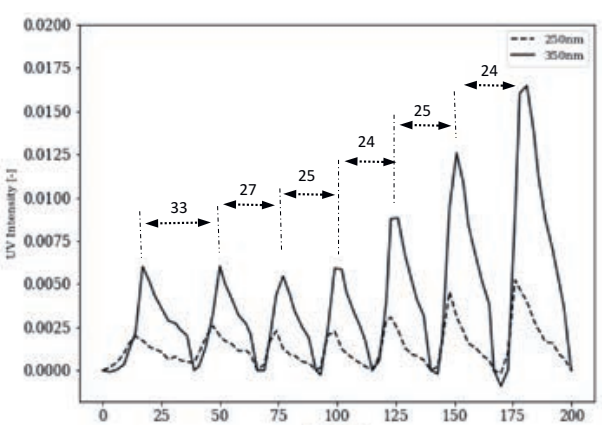

Fig. 2. Example of a control BR reaction (without antioxidants). Each peak at $250 \mathrm{~nm}$ and $350 \mathrm{~nm}$ corresponds to the appearance of blue color. Periodicity of peaks (seconds) in this measurement are shown. Reliable periodicity of 24 seconds to 25 seconds are maintained starting with $3^{\text {nd }}$ periodicity. Several replicates were conducted to establish the baseline.

to reach its regular periodicity. Starting with the third cycle, as expected from the literature, the BR reaction behaved like clockwork and a reliable baseline periodicity time (BPT) was observed in all blank runs as shown in Fig. 2 and listed in Table 1. Thus, the steady state part of BR reaction occurred after the third blue color cycle and was used as a reliable trigger point for the addition of all antioxidant measurements. The average duration of the appearance of 16 peaks ( $3^{\text {rd }}$ to $\left.6^{\text {th }}\right)$ for four blank runs done at different times during the investigation was $24.6 \pm 0.5$ seconds with range of 24 to 25 seconds (Table 1 ).

Table 1. Periodicity of the blank BR reaction across different measurements. Complete run 1 in this table is shown in Fig. 2 with its different periodicity. Steady-state was achieved starting with the 3rd period.

Average of 3rd to 6 th periods for four runs was $24.6 \pm 0.5$ seconds and used as baseline periodicity in all future calculations.

\begin{tabular}{|c|c|c|c|c|}
\hline \multirow{2}{*}{$\begin{array}{l}\text { Measure- } \\
\text { ment } \\
\text { Number }\end{array}$} & \multicolumn{3}{|c|}{ Periodicity } & \multirow{2}{*}{$\begin{array}{c}\text { Average } \\
\pm \text { SD }\end{array}$} \\
\hline & $1^{\mathrm{st}}$ & $2^{\text {nd }}$ & $3^{\text {rd }}$ to $6^{\text {th }}$ & \\
\hline 1 & 33 & 27 & $\begin{array}{l}25,24 \\
25,24\end{array}$ & $24.50 \pm 0.5$ \\
\hline 2 & 29 & 25 & $\begin{array}{l}24,25 \\
25,24\end{array}$ & $24.50 \pm 0.5$ \\
\hline 3 & 24 & 27 & $\begin{array}{r}24,24 \\
25,24\end{array}$ & $24.25 \pm 0.5$ \\
\hline 4 & 33 & 27 & $\begin{array}{l}25,25 \\
25,25\end{array}$ & $25.00 \pm 0.0$ \\
\hline
\end{tabular}

As discussed in the introduction, the BR reaction is based on a slow non-radical as well as fast free-radical reactions (Eqns (2-5)), so the addition of antioxidants should consume the radicals generated in the BR reaction leading to perturbation until all of the antioxidant is used, at which time the BR reaction should resume its periodic behavior. This duration of the perturbation, expressed as the inhibition time (IHT), can be used to quantify the amount of antioxidants. To verify this theory and check the sensitivity of the $\mathrm{BR}$ reaction to determine naturally relevant concentrations of TAC, fruit juices known to have low antioxidant (peach) and moderate antioxidant (grapefruit) contents were added separately to blank BR reactions. Fig. 3 shows the BR reaction when peach or grapefruit juice was added at the third oscillation cycle. As expected, the periodicity of this cycle was perturbed by the addition of antioxidant creating an IHT, until all antioxidant from the juice was consumed, after which the BR reaction came back to regular BPT periodicity 
of 24-25 seconds when a new steady-state is re-established after 1-2 cycles post-IHT. These experiments also show that the BR reaction is sensitive enough to pick up low amounts of antioxidants in a fruit like peach (FRAP value of peach $=0.15 \mathrm{mmol} / 100 \mathrm{~g}$, one of the lowest in fruits). ${ }^{[21,22]}$

IHT observed in Fig. 3 should be a combination of baseline periodicity (BPT in Fig. 1) and the true antioxidant periodicity time (APT) caused by antioxidant perturbing the free-radical in the BR reaction. Thus, APT due to antioxidant was calculated for all future experiments by Eqn. (6) shown below:

APT $($ antioxidant effect $)=$ IHT $($ observed $)-$ BPT $($ baseline $)$

For example in Fig. 3, APT for peach juice and grapefruit juice was estimated to be 41.4 and 103.4 seconds, respectively, based on observed IHT of 66 and 128 seconds and BPT of 24.6 seconds.
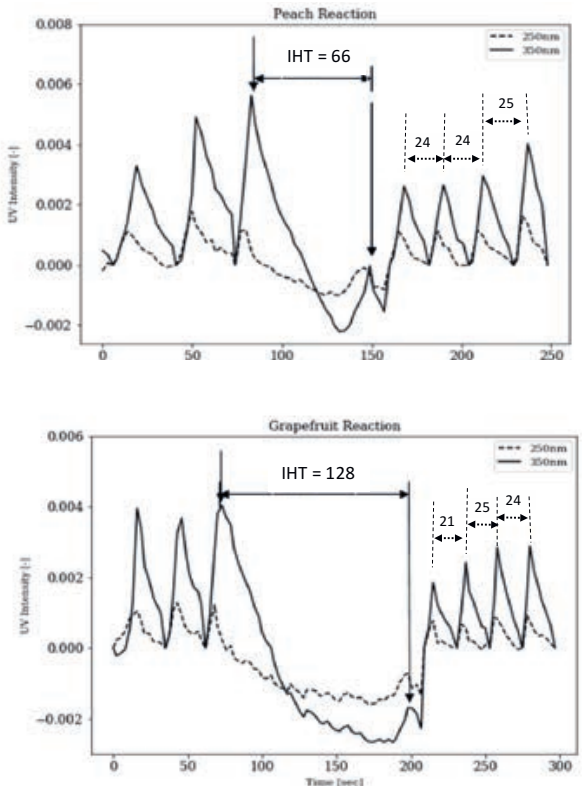

Fig. 3. Typical example of IHT during the BR reaction when fruit juices containing antioxidant were added. Fruit juice was added at the third BR peak as indicated by the first arrow. IHT and periodicity of post-IHT BR cycles are also shown. Top) addition of peach juice, IHT = 66 seconds; Bottom) addition of grapefruit juice, IHT = 128 seconds. Post-IHT periodicity returned to BPT of 24-25 seconds after steady state was reestablished during the 1-2 cycles post-IHT.

\subsection{Calibration Curve and Linearity in Response from Ascorbic Acid}

Ascorbic acid (vitamin C, AA), a well-known antioxidant, was used as the standard to establish baseline linearity of the BR reaction and later express the APT for each fruit as total antioxidant content in an easily understandable unit: ascorbic acid equivalence (AAE), which is defined as the total equivalence of vitamin $C$ that is present in the given fruit. For comparison, assays such as FRAP expresses TAC in equivalence of antioxidant in mmol of $\mathrm{Fe}^{3+}$ conversion to $\mathrm{Fe}^{2+}$ per $100 \mathrm{~g}$ of fruit. Expressing TAC as vitamin $\mathrm{C}$ equivalence may be more relevant in agricultural practices and easier to comprehend for consumers.

The low end of the AA calibration curve was selected to cover the APT from low antioxidant fruit like peach while the high end of the curve was selected to be 10-fold higher to maintain the linearity of the curve. Table 2 shows the IHT and resulting APT of AA standard solutions with varying concentrations ranging from $0.33 \mathrm{mg} / \mathrm{ml}$ to $3.30 \mathrm{mg} / \mathrm{ml}$. All experiments were done in tripli- cates and they showed low variability. Fig. 4 shows APT versus AA standard solution curve. APT follows a linear response $\left(\mathrm{r}^{2}>\right.$ 0.99) with increasing AA, suggesting that the BR reaction can be used to quantify the antioxidant quantity. However, the validity of these results to antioxidants present in complex matrices of fruits needs to be assessed before the BR reaction can be used as a potential assay for TAC.

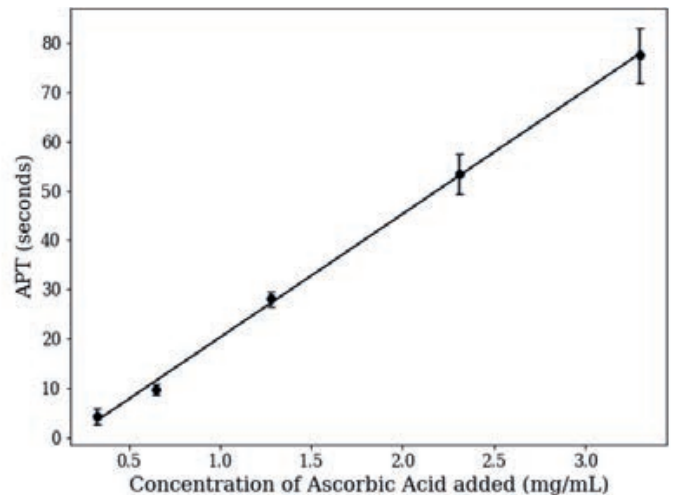

Fig. 4. APT at various concentrations of AA. Fit of data is the linear regression line $(y=24.99 x-4.70)$ with $r^{2}=0.998$.

Table 2: IHT and resulting APT in BR after addition of various amounts of $\mathrm{AA}$ at $3^{\text {rd }}$ cycle to measure the linearity of IHT with increasing concentration of $A A$. All measurements were $n=3$.

\begin{tabular}{|l|l|l|l|l|}
\hline Sample & $\begin{array}{l}\text { Ascorbic } \\
\text { Acid con- } \\
\text { certation }\end{array}$ & $\begin{array}{l}\text { Average } \\
\text { IHT }\end{array}$ & $\begin{array}{l}\text { Average } \\
\text { APT }\end{array}$ & $\begin{array}{l}\text { Standard } \\
\text { deviation }\end{array}$ \\
\hline $\begin{array}{l}\text { (mg/ml) } \\
\text { (seconds) }\end{array}$ & (seconds) & (seconds) \\
\hline $\begin{array}{l}\text { Ascorbic } \\
\text { acid }\end{array}$ & 0.33 & 29.0 & 4.4 & 1.7 \\
\hline vitamin C) & 0.65 & 34.3 & 9.8 & 1.2 \\
\hline & 1.28 & 52.7 & 28.1 & 1.5 \\
\hline & 2.31 & 78.0 & 53.4 & 4.0 \\
\hline & 3.30 & 102.0 & 77.4 & 5.6 \\
\hline
\end{tabular}

\subsection{Quantification of Antioxidant Level in Fruits and Ascorbic Acid Equivalence (AAE)}

To demonstrate that the BR reaction can quantify antioxidant levels in complex matrices of fruits, nine fruits with $>10$-fold different antioxidant amounts were selected (Table 3). Juice from each of these fruits was squeezed and filtered through 5-micron paper. 50 microliters of the juice were added to the BR reaction mixture, resulting in responses similar to Fig. 3. When the APT of any fruit juice greatly exceeded that of AA calibration curve, juice was diluted with water to stay within the calibration curve. Table 3 shows the IHT and resulting APT of each fruit. Variability in IHT was low (RSD of $<20 \%, n=3)$. APT of each fruit sample was converted to generate AAE for each fruit using the AA calibration curve. The resulting AAE value of each fruit is shown in Fig. 5. As a final check to determine the accuracy of results from the $\mathrm{BR}$ reaction, $\mathrm{AAE}$ in fruits and ranking was compared to the published TAC equivalence determined using the more expensive well-established FRAP assay. Fig. 6 shows the correlation of AAE determined in this study to TAC expressed as $\mathrm{Fe}^{3+}$ reduced by fruit in FRAP assay. There is a good correlation $\left(r^{2}>0.99\right)$ of AAE determined in this study from the BR reaction to the published data confirming that the $\mathrm{BR}$ assay is accurate in determining TAC. An added advantage of studying $\mathrm{BR}$ reaction is the intrinsic $\mathrm{pH}$ of reaction mixture of approximately 2 , which is the $\mathrm{pH}$ typically found in stomach, 
Table 3 - IHT and APT of different fruits in BR after addition of undiluted or diluted juice of different fruits. All measurements were $n=3$. *diluted 2-fold, ${ }^{* *}$ diluted 4-fold.

\begin{tabular}{|l|l|l|l|l|}
\hline Sample & Scientific Name & $\begin{array}{l}\text { Average } \\
\text { IHT }\end{array}$ & $\begin{array}{l}\text { Average } \\
\text { APT }\end{array}$ & $\begin{array}{l}\text { Standard } \\
\text { deviation }\end{array}$ \\
\hline Grape & Vitis Vinefera & 57.3 & 32.7 & 2.1 \\
\hline Peach & Prunus Persica & 62.3 & 37.7 & 6.4 \\
\hline Gala Apple & Malus Domestica & 64.0 & 39.4 & 6.2 \\
\hline Clementine & Citrus Clementina & 89.3 & 64.7 & 9.5 \\
\hline Lime & Citrus Aurantiifolia & 98.0 & 73.4 & 8.7 \\
\hline Lemon & Citrus Limon & 104.0 & 79.4 & 6.1 \\
\hline Greenstar Apple & Malus Domestica & $113.7 *$ & $89.1 *$ & 5.5 \\
\hline Grapefruit & Citrus Paradisi & 128.3 & 103.7 & 32.5 \\
\hline Pomegranate & Punica Granitum & $221 * *$ & $196.4 * *$ & 55.4 \\
\hline
\end{tabular}

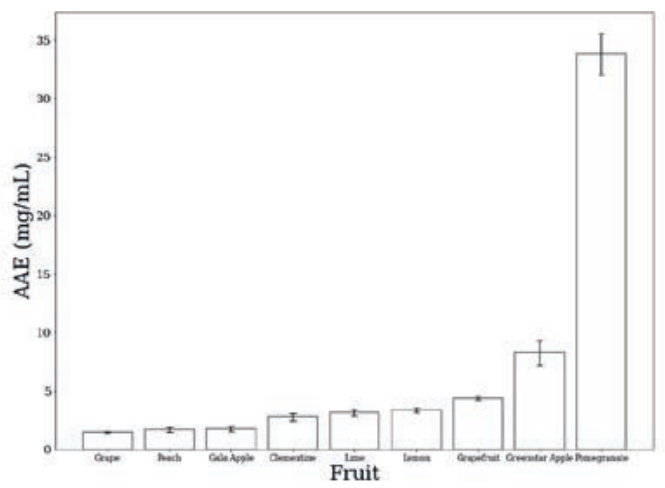

Fig. 5. Ascorbic acid equivalence (AAE) of different fruits calculated from APT of fruits juice using AA calibration curve.

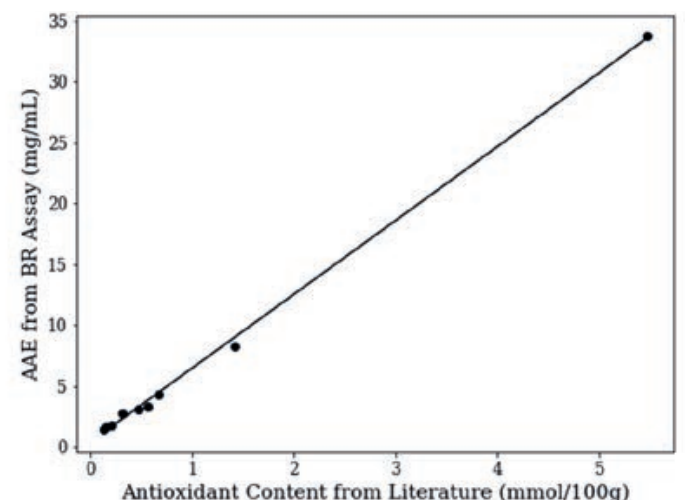

Fig. 6. AAE of fruits determined using BR assay compared to the published antioxidant values of fruits determined using widely established FRAP assays. Fit of data is the linear regression line $(y=6.06 x+0.43)$ with $\mathrm{r}^{2}=0.998$.

thus, it is a good indicator of antioxidant performance in the human body.

All chemicals used for the BR reaction (starch, potassium iodate, manganese sulphate, a keto-enol substrate such as malonic acid, and hydrogen peroxide) are cheap, widely available, and safe to use. Amount and cost of reagents for each BR reaction is an indicator of the potential cost of the BR assay. The cost of all reagents used in this study was approximately 0.15 USD per $5 \mathrm{ml}$ of $\mathrm{BR}$ reaction mixture, thus, the final cost of BR assay kit is expected to be much lower than the typical 2-3 USD per test for FRAP or ORAC assay kits. A logical extension of this work will be to further simplify the experimental set up by using visual color instead of a UV/Vis probe to make it commercially available for use in agricultural, rural settings or other parts of world. To give confidence that a visual endpoint is possible, all work presented in this study was re-analyzed based on only visual appearance of blue-black color seen by the naked eye (only using IHT without correcting for BPT). All AAE values for fruits remained accurate to published FRAP values suggesting use of color endpoint by end users is possible. In addition, more work is needed to confirm the general applicability of AAE from the BR assay to other type of food groups. But, based on these experiments, it is expected to apply widely for other water-soluble TACs.

\section{Conclusion}

The BR reaction provides an excellent underlying chemistry for this antioxidant assay because it was found to be as accurate as the well-established antioxidant assays such as FRAP, while using safe and cheap chemicals so no special precaution of packaging is needed for using assay kits. In addition the end point is a sharp color change from amber to blue that can be monitored visually and the assay is very quick to do (typically 5 minutes). Simplification of the monitoring of the BR reaction by simple visual assessment or UV/Vis spectrometric measurements, instead of using potentiometric or cyclic voltammetry measurements, renders this approach much easier to use in educational institutions. This can be used to energize and motivate students early in their career to start thinking of how existing chemistry knowledge of the BR reaction can be easily applied to solve real-world problems. The concept and data presented here can also be seen as an invitation for an organization or a start-up company to develop commercial BR assays kits that can be readily shipped to farmers, labs in rural areas and/or parts of world where cost is a much bigger issue.

\section{Acknowledgements}

We would like to sincerely thank Stefan Hildbrand for being a great mentor during this work and provide the infrastructure that was needed to perform this study. Without his help this work would not have been possible. Also, we want to acknowledge to Florian Koch at ETH Zurich for his advice during this project.

Received: August 26, 2020

[1] A. Yashin, Y. Yashin, X. Xia, B. Nemzer, Antioxidants 2017, 6, 70, https://doi.org/10.3390/antiox6030070

[2] H. N. Siti, Y. Kamisaha, J. Kamsiaha, Vascular Pharmacol. 2015, 71, 40, https://doi.org/10.1016/j.vph.2015.03.005

[3] I. Gülçin, Arch. Toxicol. 2012, 86, 345, https://doi.org/10.1007/s00204-011-0774-2

[4] H. Jaberie, S. Momeni, I. Nabipour, Microchem. J. 2020, 157, 104908, https://doi.org/10.1016/j.microc.2020.104908

[5] F. Shahidi, Y. Zhong, J. Funct. Foods 2015, 18, 757, https://doi.org/10.1016/j.jff.2015.01.047

[6] K. Moon, T. Shibamoto, J. Agric. Food Chem. 2009, 57, 1655 , https://doi.org/10.1021/jf803537k

[7] N. Chaves, A. Santiago, J. C. Alías, Antioxidants, 2020, 9, 76, https://doi.org/10.3390/antiox 9010076

[8] T. S. Briggs, W. C. Rauscher, J. Chem. Educ. 1973, 50, 496, https://doi.org/10.1021/ed050p496

[9] J. Gajdos Kljusurić, S. Djaković, I. Kruhak, K. G. Kovačević, D. Komes, Z. Kurtanjek, Acta Alimentaria 2005, 34, 483 , https://doi.org/10.1556/aalim.34.2005.4.15

[10] K. Höner, R. Cervellati, Eur. Food Res. Technol. 2002, 215, 437 , https://doi.org/10.1007/s00217-002-0582-2

[11] M. Pribus, L. Trnková, O. Grančičová, A. Olexová, Int. J. Chem. Kinetics 2018, 50, 481, https://doi.org/10.1002/kin.21174

[12] E. Prenesti, S. Toso, S. Berto, J. Agric. Food Chem. 2005, 53, 4220, https://doi.org/10.1021/jf048302y

[13] S. Furrow, R. Cerevellati, E. Greco, Zeits. Naturforschung B 2012, 67, https://doi.org/10.1515/znb-2012-0115 
[14] L.-I. Csepei, C. Bolla, Studia Universitatis Babes-Bolyai Chemia 2009, 4, 249.

[15] M. Pribus, L. Trnková, Chemistry Select 2018, 3, 10951, https://doi.org/10.1002/slct.201802373

[16] S. S. Furrow, J. Chem. Educ. 2012, 89, 1421, https://doi.org/10.1021/ed200764r

[17] N. Okazaki, I. Hanazaki J. Chem. Phys. 1998, 109, 637, https://doi.org/10.1063/1.476602

[18] R. M. Noyes, S. D. Furrow, J. Am. Chem. Soc. 1982, 104, 45, https://doi.org/10.1021/ja00365a011

[19] F. D’Alba, S. Lorenzo, J. Electroanal. Chem. Interf. Electrochem. 1983, $156,435$.

[20] S. D. Furrow. K. Höner, R. Cervellati, Helv. Chim. Acta 2004, 87, 735, https://doi.org/10.1002/hlca.200490068

[21] D. Haytowitz. S. Bhagwat, USDA Database for ORAC of Selected Food, Release 2, 2010, https://www.ars.usda.gov/research/publications/ publication/?seqNo115=251105, accessed August 18, 2020.
[22] M. H. Carlsen, B. L. Halvorsen, K. Holte, S. K. Bøhn, S. Dragland, L. Sampson, C. Willey, H. Senoo, Y. Umezono, C. Sanada, I. Barikmo, N. Berhe, W. C. Willett, K. M. Phillips, D. R. Jacobs Jr, R. Blomhoff, Nutrition J. 2010, 9, 3, https://doi.org/10.1186/1475-2891-9-3

\section{License and Terms}

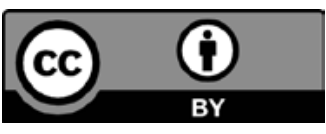

This is an Open Access article under the terms of the Creative Commons Attribution License CC BY 4.0. The material may not be used for commercial purposes.

The license is subject to the CHIMIA terms and conditions: (http:// chimia.ch/component/sppagebuilder/?view=page\&id=12).

The definitive version of this article is the electronic one that can be found at https://doi.org/10.2533/chimia.2021.74 